Article

\title{
High Quality Graphene Thin Films Synthesized by Glow Discharge Method in A Chemical Vapor Deposition System Using Solid Carbon Source
}

\author{
Le Wang ${ }^{1}$, Jie Sun ${ }^{2,3, * \mathbb{D}}$, Weiling Guo ${ }^{1, \dagger}$, Yibo Dong ${ }^{1}$, Yiyang Xie ${ }^{1}$, Fangzhu Xiong ${ }^{1}$, Zaifa Du ${ }^{1}$, \\ Longfei $\mathrm{Li}^{1}$, Jun Deng ${ }^{1}$ and Chen $\mathrm{Xu}^{1}$ \\ 1 Key Laboratory of Optoelectronics Technology, Beijing University of Technology, Beijing 100124, China; \\ wangle316@emails.bjut.edu.cn (L.W.); guoweiling@bjut.edu.cn (W.G.); donyibo@emails.bjut.edu.cn (Y.D.); \\ xieyiyang@bjut.edu.cn (Y.X.); fangzhuxiong@emails.bjut.edu.cn (F.X.); 17801011216@163.com (Z.D.); \\ 18800153166@163.com (L.L.); dengsu@bjut.edu.cn (J.D.); xuchen58@bjut.edu.cn (C.X.) \\ 2 National and Local United Engineering Laboratory of Flat Panel Display Technology, College of Physics and \\ Information Engineering, Fuzhou University, Fuzhou 350100, China \\ 3 Fujian Science \& Technology Innovation Laboratory for Optoelectronic Information of China, \\ Fuzhou 350100, China \\ * Correspondence: jie.sun@fzu.edu.cn \\ + Contributed equally to this work.
}

Received: 19 February 2020; Accepted: 8 April 2020; Published: 26 April 2020

check for updates

\begin{abstract}
Arc discharge is traditionally used to synthesize randomly arranged graphene flakes. In this paper, we substantially modify it into a glow discharge method so that the discharge current is much more reduced. The $\mathrm{H}_{2}$ and/or Ar plasma etching of the graphitic electrode (used to ignite the plasma) is hence much gentler, rendering it possible to grow graphene in thin film format. During the growth at a few mbar, there is no external carbon gas precursor introduced. The carbon atoms and/or carbon containing particles as a result of the plasma etching are emitted in the chamber, some of which undergo gas phase scattering and deposit onto the metallic catalyst substrates (Cu-Ni alloy thin films or $\mathrm{Cu}$ foils) as graphene sheets. It is found that high quality monolayer graphene can be synthesized on $\mathrm{Cu}$ foil at $900{ }^{\circ} \mathrm{C}$. On Cu-Ni, under the same growth condition, somewhat more bilayer regions are observed. It is observed that the material quality is almost indifferent to the gas ratios, which makes the optimization of the deposition process relatively easy. Detailed study on the deposition procedure and the material characterization have been carried out. This work reveals the possibility of producing thin film graphene by a gas discharge based process, not only from fundamental point of view, but it also provides an alternative technique other than standard chemical vapor deposition to synthesize graphene that is compatible with the semiconductor planar process. As the process uses solid graphite as a source material that is rich in the crust, it is a facile and relatively cheap method to obtain high quality graphene thin films in this respect.
\end{abstract}

Keywords: graphene; glow discharge; graphite; chemical vapor deposition; metal catalyst; solid carbon source; plasma

\section{Introduction}

Since its appearance, graphene has been applied to solar cells, sensors, composite materials, photocatalysis, and other fields due to its outstanding characteristics such as high carrier mobility, high mechanical strength, high specific surface area, high transmittance, and high thermal conductivity [1]. The graphene synthesis methods include mechanical exfoliation, chemical exfoliation, epitaxial graphene on SiC [2], molecular beam epitaxy (MBE) [3], chemical vapor deposition (CVD) [4], 
and arc discharge (AD) [5-13], etc. Among these technologies, mechanical and chemical exfoliation of graphite can only produce irregular shaped flakes or powders; epitaxial graphene on $\mathrm{SiC}$ is hardly transferable, very expensive, and the graphene film size is limited by the available $\mathrm{SiC}$ substrate; MBE graphene is not mature and the material quality is modest; only CVD technique can produce scalable graphene thin films that are compatible with standard semiconductor planar process. Regarding $\mathrm{AD}$, because of the low controllability, it has not received widespread attention in graphene synthesis thus far. Traditionally, the AD method is used to synthesize fullerenes, single or multi-wall carbon nanotubes, randomly arranged graphene flakes, carbon nanoparticle-based light-emitting devices, etc. [5-13]. When making graphene by $\mathrm{AD}$, the graphite electrode is usually used as the carbon source. Typically, the electrode can be completely consumed in just ten minutes or so due to the high electrical current and the intense etching reaction, and the graphene grown is multi-layered (about 2 to 10 layers) and very defective [5-13]. A variant version of the AD method is the synthesis of graphene by the so-called hydrogen $\mathrm{AD}$ exfoliation of graphite, which is often with the involvement of graphene oxides [13]. Nevertheless, it is also not very controllable and, most importantly, it is not compatible with today's semiconductor processing and cannot produce graphene in the format of thin films.

In this paper, we have substantially modified the traditional AD method, based on which we introduce a new graphene synthesis technique that is called the glow discharge (GD) deposition method. The equipment used in this work is actually a standard PECVD (plasma enhanced CVD) system that was not originally intended for the GD use. In the chamber, which is filled with $\mathrm{H}_{2}$ and/or Ar gas, we ignited the plasma, and it slightly etches the graphite electrode that is used to start the plasma. Because of this, we were able to grow graphene on the surface of metal catalysts even without using any carbon precursor gas. The possible deposition mechanism is explained by the plasma-based physical and/or chemical etching of the graphitic electrode, followed by gas phase scattering of the produced carbon atoms and carbon based particles, which are in part transported towards the catalytic surfaces of the metallic substrates situated on the heater. After the catalytic graphitization on the metal surface, the prepared graphene/metal is unloaded, and the graphene can be transferred to insulators using a wet etching-based technique [14,15]. The parameters of the GD method are systematically optimized, and the materials are characterized in detail. Compared with MBE, partly due to the existence of catalyst, the GD offers a better material quality, and the growth time is also much shorter. Even including the pumping and heating/cooling procedure, it only takes $20 \mathrm{~min}$ for one run. Compared to standard CVD, the GD offers an alternative method that negates the need for work on the precursor gas composition, the decomposition rate, and the large growth parameter space. Furthermore, the growth temperature of GD is somewhat lower. Compared to AD, the GD here is a much gentler process. Most importantly, the graphene prepared by GD is a continuous thin film with high quality, which can be transferred to insulators and used to make electronic devices. Our work explores the potential of the traditionally overlooked AD method in synthesizing graphene thin films that are compatible with semiconductor planar processing. Therefore, it is of value to scientists and engineers who work with the synthesis of graphene and its electronic device applications.

\section{Experimental Procedures and Methods}

In order to verify and benchmark the quality of the graphene obtained by the new GD graphene production mode proposed in this paper, we first grow standard graphene thin films by CVD using two kinds of conventional catalytic metals (Cu-Ni alloy film and copper foil) $[16,17]$ as control samples. The CVD process is described in our earlier publication [14,15]. Those two types of metals are also the substrates that are used to grow graphene by our GD method, and their preparation methods are as follows.

(1) $\mathrm{Cu}-\mathrm{Ni}$ alloy thin films. After the $\mathrm{Si}$ wafer is cleaned by standard procedure, $300 \mathrm{~nm} \mathrm{SiO} \mathrm{S}_{2}$ is grown by inductively coupled plasma chemical vapor deposition (ICP-CVD). This is because, later, the $\mathrm{Cu}-\mathrm{Ni}$ will be removed and the grown graphene will "land" on the $\mathrm{SiO}_{2}$, and $300 \mathrm{~nm}$ silicon dioxide is known to facilitate the observation of graphene under an optical microscope after growth, due to the 
optical interference effect [18]. Magnetron sputtering is used to sputter Cu-Ni (2:1) alloys of different thicknesses on the $\mathrm{SiO}_{2} / \mathrm{Si}$ wafers to study the effect of catalyst thickness on the quality of graphene.

(2) Copper foils. High purity polycrystalline copper foils are purchased commercially.

The growth system used in this work is a graphene PECVD of the model Black Magic, produced by Aixtron Nanoinstruments Ltd. The outwall of the growth chamber is made of stainless steel with a quartz shield as the inwall. As shown in Figure 1, gases come from the top via a quartz showerhead, which has small holes to distribute the gases uniformly to the samples below. The arrows indicate the direction of the gas flow. The samples are placed on a graphitic heater supported by two vertical metal rods which are also working as the heater electrodes. Alternating current (AC) current is sent through the two electrodes to heat the heater by Joule heating. On the heater, there is a ceramic clamp which can hold a maximum 2 inch sample. A third electrode, which we call the plasma electrode, is right below the heater (with $\sim 4 \mathrm{~cm}$ distance). An AC or direct current (DC) voltage of several hundred volts can be applied to the plasma electrode, with respect to the potential of the heater in order to ignite the plasma (In this paper we have used the AC configuration).

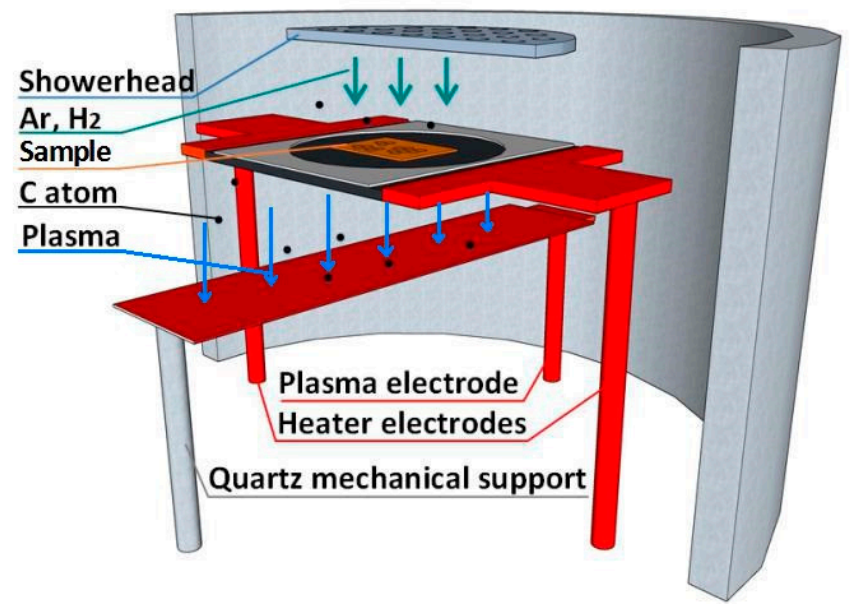

Figure 1. Schematic illustration of the growth chamber of the plasma enhanced chemical vapor deposition (PECVD) equipment which is used for the glow discharge (GD) synthesis of graphene in this work.

We place the as-prepared $\mathrm{Cu}-\mathrm{Ni}$ alloy thin film or copper foil samples on the graphite plate heater in the equipment (see Figure 1) for the GD growth of graphene. The copper foil sample, however, should be first put in a quartz bowl, because if the foil is in direct contact with the heater, the electrical current leaked into the copper from the graphite is hard to control, which will add extra heating and may melt the copper. After evacuating to a base pressure of $2 \times 10^{-3} \mathrm{kPa}$, we introduce Ar and/or $\mathrm{H}_{2}$ gases (for example, with a ratio of 5:1) into the chamber, and the pressure reaches $5 \times 10^{-1} \mathrm{kPa}$. The procedure is repeated three times and then the gas input is turned off. This is because we have found that without a flowing gas, the plasma power during the initiation is more stable than is the case with a gas flow. The heating rate is $5^{\circ} \mathrm{C} / \mathrm{s}$, at which we increase the heater temperature to the desired growth temperature (typically $600-1000{ }^{\circ} \mathrm{C}$ ). The samples are held at this temperature for ten minutes for annealing to increase the crystallinity of the metals [19], which is especially useful for the $\mathrm{Cu}-\mathrm{Ni}$ alloy. Then, the plasma is ignited. The power intensity is $40 \mathrm{~W}$, and the AC frequency is $20 \mathrm{kHz}$. After $5 \mathrm{~min}$ of growth, the plasma is turned off, and the temperature is cooled down to $500{ }^{\circ} \mathrm{C}$ at a rate of $5{ }^{\circ} \mathrm{C} / \mathrm{s}$. Afterwards, the Ar gas is introduced to the chamber to accelerate the temperature dropping until it is cooled to room temperature, and the samples are unloaded.

After growth, the copper-nickel alloy and the copper foil samples are all spin-coated (4000 rpm for $30 \mathrm{~s})$ with a layer of polymethyl methacrylate (PMMA) with about $70 \mathrm{~nm}$ thickness. Then, it is heated on a $150{ }^{\circ} \mathrm{C}$ hot plate for $10 \mathrm{~min}$. A metal etching solution $\left(\mathrm{CuSO}_{4}: \mathrm{HCl}: \mathrm{H}_{2} \mathrm{O}=5 \mathrm{~g}: 25 \mathrm{~mL}: 50 \mathrm{~mL}\right)$ is 
prepared. The copper-nickel sample is placed at the bottom of the beaker, whereas the copper foil sample is floating on the surface of the solution. The copper foil grown graphene is transferred to another $300 \mathrm{~nm} \mathrm{SiO} / / \mathrm{Si} \mathrm{substrate} \mathrm{by} \mathrm{the} \mathrm{standard} \mathrm{wet} \mathrm{transfer} \mathrm{process} \mathrm{[14,15].} \mathrm{The} \mathrm{graphene} \mathrm{grown} \mathrm{on}$ the $\mathrm{Cu}-\mathrm{Ni}$ alloys, however, is transferred to its own $\mathrm{SiO}_{2} / \mathrm{Si}$ substrate through the etching mechanism that is shown in Figure 2. The chemical solution penetrates the PMMA and etches the metal beneath. Because of the buffering of the PMMA layer, the reaction will become very gentle, which reduces the possibility of graphene being damaged by the etching process [17]. After etching, we put the $\mathrm{PMMA} / \mathrm{graphene} / \mathrm{SiO}_{2} / \mathrm{Si}$ complex in deionized water for $30 \mathrm{~min}$ to clean up the residual chemicals. In order to improve the adhesion between the graphene and the substrate, it is baked at $150{ }^{\circ} \mathrm{C}$ for $15 \mathrm{~min}$ on a hot plate. Then, it is placed in acetone for $1 \mathrm{~h}$ to remove the PMMA from graphene. Finally, the sample is placed in a ventilated place for $10 \mathrm{~min}$ to dry the acetone. During the experiment, nevertheless, after the metal etching the van der Waals force between the $\mathrm{SiO}_{2} / \mathrm{Si}$ substrate and the PMMA/graphene is relatively weak, and the rinsing process in deionized water might cause the PMMA/graphene to float on the surface of solution. Applying a little PMMA to the edges of the sample helps hold the film, and can increase the success rate of the graphene transfer.

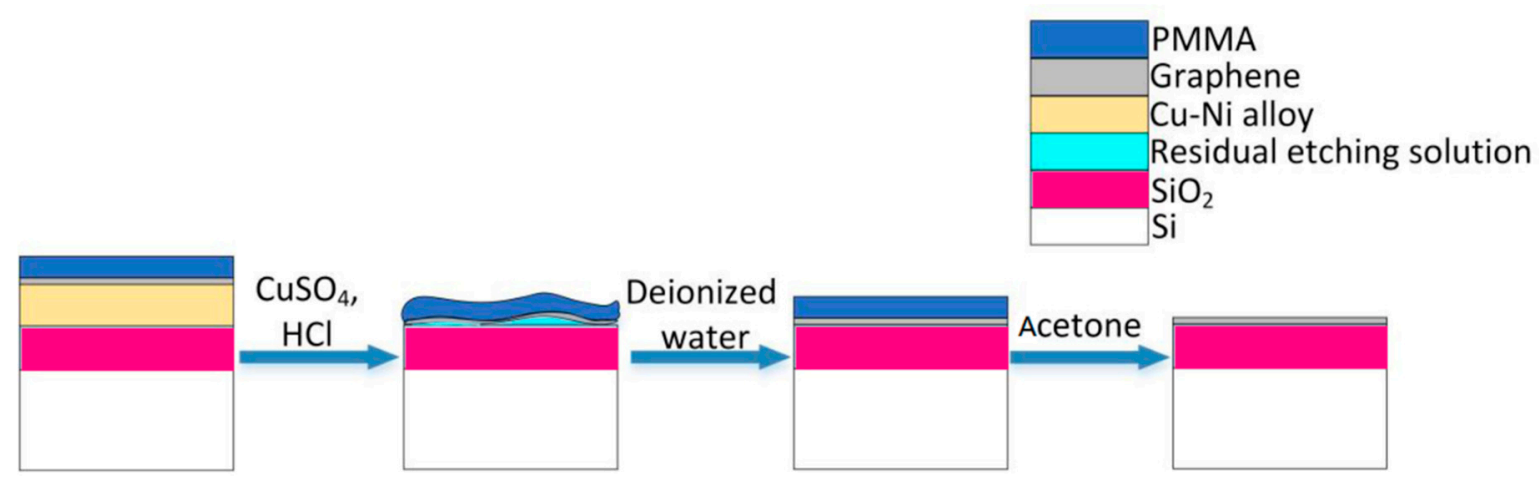

Figure 2. Process of "transferring" the graphene grown by $\mathrm{Cu}-\mathrm{Ni}$ alloy onto its own $\mathrm{SiO}_{2} / \mathrm{Si}$ substrate.

After the sample preparation, we use Raman spectroscopy with the excitation wavelength at $532 \mathrm{~nm}$ to characterize the quality of the graphene thin films, as well as to determine the number of graphene layers grown with different metal catalysts. Raman mapping is also performed. A scanning electron microscope (SEM, MERLIN Compact, Zeiss, Oberkochen, Germany) is used to examine the morphology of the metals after the annealing and after the graphene deposition.

\section{Results and Discussion}

The schematic illustration of the graphene deposition procedure is shown in Figure 3a. The production mechanism of graphene involves two steps: (1) the creation of carbon atoms or carbon containing particles; (2) the graphitization of these particles. Regarding the graphitization on the substrate, it is the same for both the GD growth method and the normal graphene CVD. However, in a regular CVD, the formation of carbon atoms or carbon containing particles is via the decomposition of hydrocarbons, whereas in GD it is through the gentle plasma etching of the electrode. The possible carbon particle formation mechanism of our GD method is explained as follows. GD and AD are two typical discharge procedures of gaseous species. Compared to the traditional AD method, the process in our GD is much gentler. Usually, GD occurs at a higher and more stable voltage, but the current is smaller (in $\mathrm{mA}$ ). AD happens at lower voltage (typically 1 10 V), but the current is in ampere range (typically 10 100 A). It's often much brighter and hotter compared to GD. In our machine, the applied plasma voltage is in the order of several 100 volts, the current is $0.1-0.5 \mathrm{~A}$, and the pressure is a few mbar. These are typical conditions for GD but not for AD [20]. Under our condition, therefore, the phenomenon should be defined as GD instead of $\mathrm{AD}$, which is a lot gentler. The plasma etches the graphite, but does not exfoliate it like in the AD. The emitted carbon atoms and carbon containing 
particles are graphitized into textured thin films on the metal surfaces. That eliminates the possibility to produce random graphene flakes as the $\mathrm{AD}$ method does. We have not found any reports about graphene thin films produced by AD. Therefore, the graphene produced by AD cannot be applied in electronic chips. It is mainly for other applications such as composite materials. In our GD, on the other hand, as shown later, no matter what $\mathrm{Ar}$ to $\mathrm{H}_{2}$ gas ratios are used, we can always obtain thin film graphene conformally coating on the metal catalysts, provided that other conditions are optimized (e.g., temperature, pressure, plasma power). Since there is no carbon containing gas introduced in the machine, the only explanation is that the graphene grows from the etched graphite. Note that we have found the graphene thin films do not form when no plasma is present. Thus, we can conclusively exclude the possibility that the graphene's carbon source comes from unintentionally introduced carbon species in the chamber such as carbon contamination, oil vapor from the pump, etc. In our experiment, the etching mechanisms of $\mathrm{H}_{2}$ and Ar plasmas are different. The former $\left(\mathrm{H}_{2}\right.$ plasma $)$ is mainly a chemical process, where the etching of graphite is achieved through hydrogenation (forming $\mathrm{C}-\mathrm{H}$ bonds) and the subsequent releasing of hydrocarbons such as $\mathrm{CH}_{4}$ [21]. Some authors, however, suggest a slightly different mechanism, where the hydrocarbon formation is a result of first ionic bombardment and subsequent chemical reaction [22]. The latter (Ar plasma) is basically a physical process, where the etching is simply an ionic bombardment and creates carbon atoms [23,24]. So, how can those carbon atoms or carbon-based particles that resulted from the etched graphite turn into graphene thin films? When the plasma electrode is etched, the produced particles are transported onto the catalytic metal substrates via gas phase scattering. The mean free path $\lambda$ of the particles can be approximately estimated by the ideal gas formula $\lambda=\frac{1}{\sqrt{2} \pi d^{2} n}$, where $d$ is the effective diameter of the particle, and $n$ is the number of particles per unit volume. Using that equation, the mean free path of the carbon-based particles is in the order of a few millimeters, which is much shorter than the distance between the plasma electrode and the samples on the heater $(\sim 4 \mathrm{~cm})$. Therefore, the particles undergo many scatterings in the chamber and some particles will have chances to be directed toward the samples, as depicted in Figure 3a. In fact, since the graphite heater is also immersed in the plasma, it can be slightly etched, and supply some of the carbon particles as well. Because of the existence of the catalysts, graphitization happens on their flat surfaces and graphene thin films grow therein.

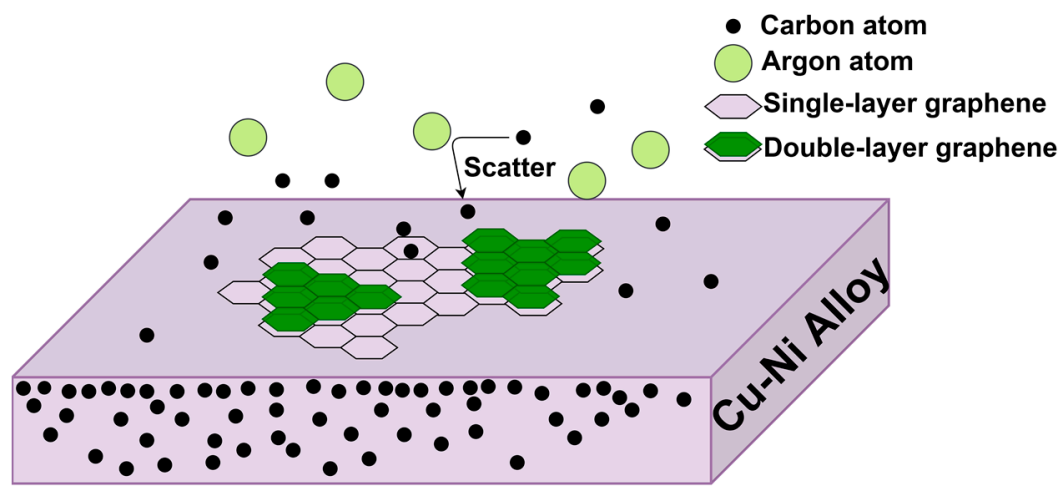

(a)

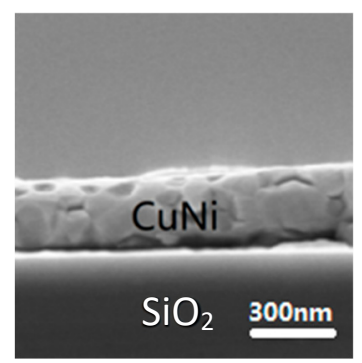

(b)

Figure 3. (a) Schematic diagram of the deposition of graphene by GD method on the Cu-Ni alloy. The carbon atoms resulted from the plasma etching of the graphite electrode are transported to the metal catalytic surface via scattering. (b) Scanning electron microscope (SEM) image (cross-sectional view) of the Cu-Ni alloy after annealing at $900{ }^{\circ} \mathrm{C}$.

The introduction of the GD production mode in the PECVD chamber makes it feasible to grow thin film graphene under our conditions, which is not possible in the traditional AD method, which can only produce chaotic flakes. That is a new feature in graphene synthesis by gas phase discharge, both from fundamental and application points of view. Furthermore, in the GD method, the graphene is grown from cheap graphite and not an expensive carbon precursor gas, reducing the cost in this 
regard. Also, because there is no carbon precursor gas, it makes the process optimization much easier, without the need to monitor the precursor gas ratios. Only $\mathrm{H}_{2}$ and/or Ar gases are required in the chamber. As can be seen later, the quality of graphene is insensitive to the $\mathrm{H}_{2}$ to Ar ratio. According to our experiment, the material quality can be optimized by adjusting parameters such as the type of catalytic metals and the deposition temperature. Finally, after the GD growth, we have measured the $300 \mu \mathrm{m}$ thick plasma electrode and could not detect any weight loss. Therefore, the process is indeed very gentle, and the consumption of the graphite material is tiny. In our practice, the same graphite electrode can be used for hundreds of runs.

In Figure $3 b$, the cross-sectional morphology of the $\mathrm{Cu}-\mathrm{Ni}$ alloy after annealing can be seen. The Cu-Ni thin film thickness is $300 \mathrm{~nm}$. It can be seen that the film is rather flat, and the copper and nickel have been uniformly alloyed after the annealing at $900^{\circ} \mathrm{C}$. The Raman results of the $\mathrm{Cu}-\mathrm{Ni}$ alloy grown graphene samples can be seen in Figure 4a. The $\mathrm{G}$ band appears in each curve as a typical signature of a sp $\mathrm{s}^{2}$ hybridized graphitic carbon structure. As the temperature rises from $600{ }^{\circ} \mathrm{C}$ to $1000^{\circ} \mathrm{C}$, the characteristic $2 \mathrm{D}$ peaks of the graphene Raman spectroscopy gradually appear. Meanwhile, the $\mathrm{D}$ peak eventually decreases. These features indicate that the number of defects or disorders in the graphene decreases. The Raman characterization results of the samples at $800{ }^{\circ} \mathrm{C}-1000{ }^{\circ} \mathrm{C}$ are more or less similar to each other. The Raman results are also comparable with standard CVD graphene grown in the same type of machine (see our previous publications [14,15]), which confirms the crystalline quality of the as-grown graphene. The feasibility of using the GD method to grow reasonably high-quality graphene with catalyst at around $900^{\circ} \mathrm{C}$ is thus experimentally proved.

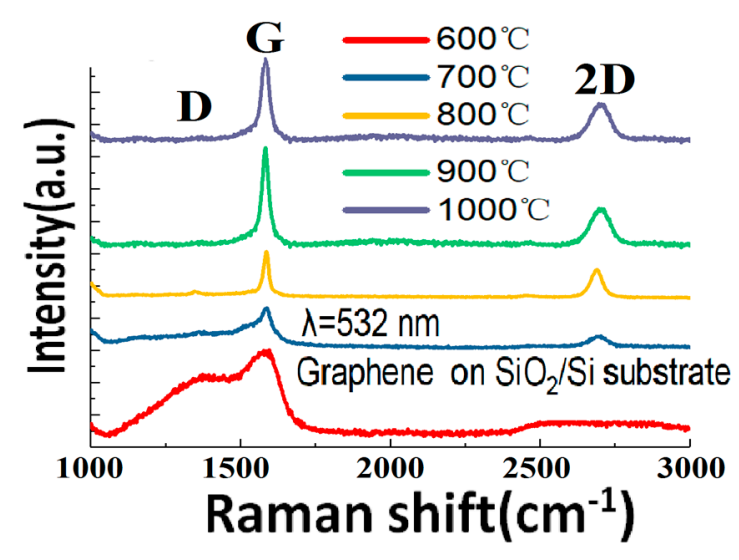

(a)

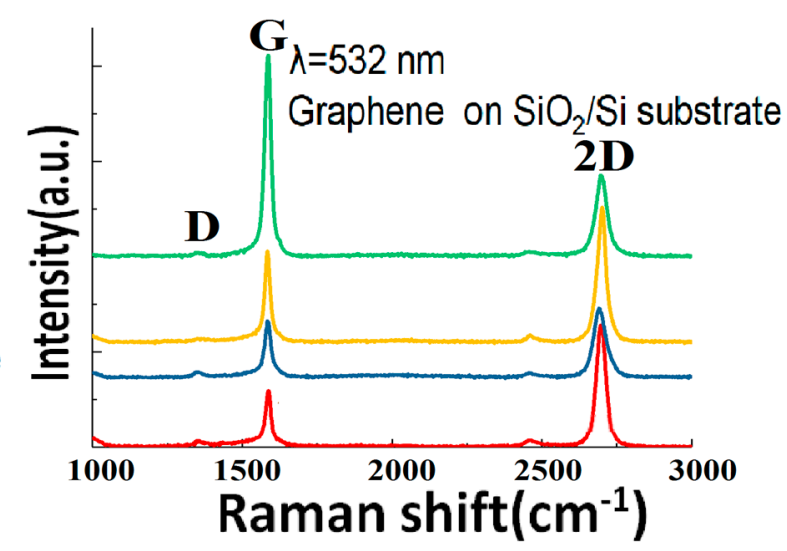

(b)

Figure 4. (a) Raman spectra of the graphene grown at different temperatures on Cu-Ni alloy and transferred to $\mathrm{SiO}_{2} / \mathrm{Si}$ substrates. (b) Raman spectra captured at different positions in the same graphene sheet grown on a $\mathrm{Cu}-\mathrm{Ni}$ alloy at $900{ }^{\circ} \mathrm{C}$ and transferred to its $\mathrm{SiO}_{2} / \mathrm{Si}$ substrate.

In order to examine the structural uniformity of the graphene along the sample, more detailed characterizations are carried out. Figure $4 \mathrm{~b}$ shows the Raman spectra measured at different positions of the same graphene sheet grown at $900{ }^{\circ} \mathrm{C}$ on a $\mathrm{Cu}-\mathrm{Ni}$ alloy and transferred to its $\mathrm{SiO}_{2} / \mathrm{Si}$ substrates. It is well established that the number of layers in graphene with good crystallinity can be estimated through the 2D/G ratio, and the shape and width of the peaks [25]. It can be seen that the number of graphene layers grown by the $\mathrm{Cu}-\mathrm{Ni}$ alloy varies between monolayer, bilayer, and multilayers at different locations across the surface of the substrate. This is explained by the carbon segregation mechanism during the graphene growth on the metal [26], because the nickel content in the alloy has a high carbon solubility of 1.26 at.\% [27] (see Figure 3a). Apart from the surface catalysis process, the dissolved carbon species can emit to the surface of the alloy upon cooling down, as a result of the reduced carbon solubility at lower temperature. Subsequently, at some areas the graphene layers are thicker due to the carbon segregation. If $\mathrm{Cu}$ is used as the catalyst, then the dominant growth mechanism is a surface catalytic graphitization procedure, because the carbon solubility is very low 
(only 0.0027 at.\% [27]). Therefore, we have also grown graphene on copper foils without any Ni content, in order to obtain a large monolayer ratio, as will be shown thereinafter.

Figure 5a shows the Raman spectra of graphene samples (transferred to $\mathrm{SiO}_{2} / \mathrm{Si}$ ) grown on a $300 \mathrm{~nm} \mathrm{Cu}-\mathrm{Ni}$ alloy with different gas ratios at $900{ }^{\circ} \mathrm{C}$. The gas mixture is varied from pure $\mathrm{Ar}, \mathrm{Ar}: \mathrm{H}_{2}$ $=5: 1, \mathrm{Ar}: \mathrm{H}_{2}=5: 3, \mathrm{Ar}: \mathrm{H}_{2}=5: 5$, to pure $\mathrm{H}_{2}$. It can be seen that the graphene quality almost does not change, which proves that the GD mechanism does not depend much on the $\mathrm{Ar}-\mathrm{H}_{2}$ composition of the gas. No matter whether it is a large atom Ar gas or a small molecule $\mathrm{H}_{2}$ gas, the GD can etch the graphite electrode and supply carbon source anyway (although the etching mechanisms are different). Therefore, in future experiments, cheaper gas can be selected to prepare the graphene by this method. However, because the reaction temperature is typically above $800{ }^{\circ} \mathrm{C}$, oxygen or air cannot be selected as the plasma gas so as to avoid the burning of the graphite.

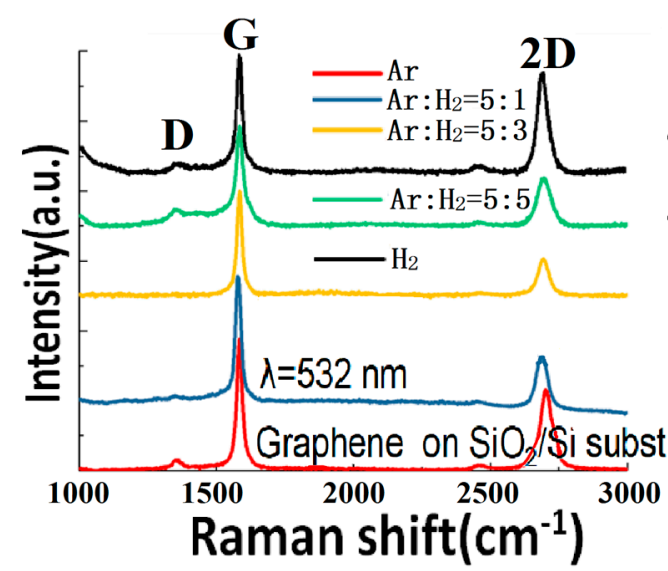

(a)

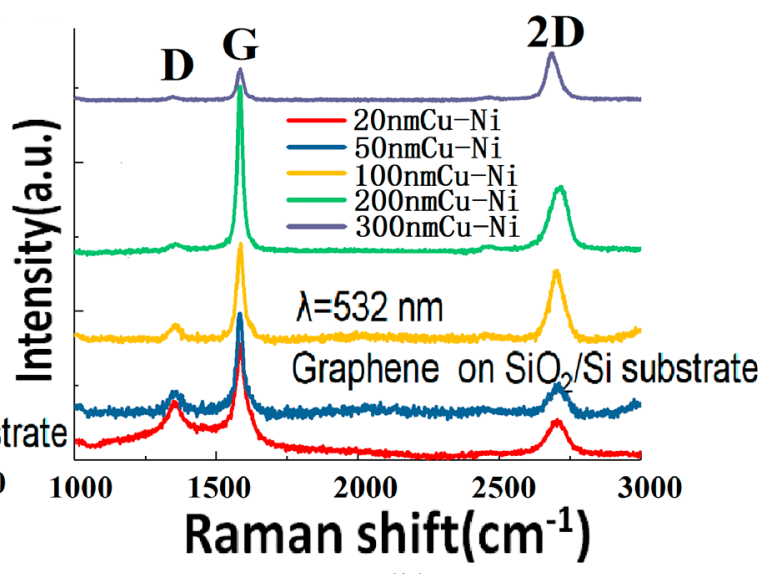

(b)

Figure 5. (a) Raman spectra of the graphene thin films grown with different gas ratios at $900{ }^{\circ} \mathrm{C}$ on $300 \mathrm{~nm} \mathrm{Cu}-\mathrm{Ni}$ and transferred to $\mathrm{SiO}_{2} / \mathrm{Si}$ substrates. (b) Raman spectra of the graphene grown at $900{ }^{\circ} \mathrm{C}$ (transferred to $\mathrm{SiO}_{2} / \mathrm{Si}$ ) and $\mathrm{Ar}: \mathrm{H}_{2}$ (5:1) gas ratio with different thicknesses (from 20 to $300 \mathrm{~nm}$ ) of $\mathrm{Cu}-\mathrm{Ni}$ alloy

Figure $5 b$ shows the Raman spectra of the graphene (transferred to $\mathrm{SiO}_{2} / \mathrm{Si}$ ) grown at $900{ }^{\circ} \mathrm{C}$ with a different thicknesses (from 20 to $300 \mathrm{~nm}$ ) of $\mathrm{Cu}-\mathrm{Ni}$ alloy and an $\mathrm{Ar}: \mathrm{H}_{2}=5: 1$ gas ratio. The original idea of this experiment was to reduce the amount of absorbed carbon (hence reducing the number of produced graphene layers) through reducing the thickness of the $\mathrm{Cu}-\mathrm{Ni}$ alloy. However, the experimental results show that even if the $20 \mathrm{~nm} \mathrm{Cu}-\mathrm{Ni}$ alloy is used, it still can produce bilayer and multilayer graphene. On the other hand, as the thickness decreases, the D peak rises and more defects appear. This article considers that the graphene quality gets worse at reducing thickness of the alloy because during the growth, the metals of the $20 \mathrm{~nm}$ and $50 \mathrm{~nm}$ samples sublimate from the surface under high temperature and low pressure conditions, which gradually leads to the loss of the graphene catalysis effect. If we continue to test the growth on even thinner metals, the graphene quality will be even worse, and the alloy will melt due the lowering of the melting point with the reduction of the thickness. Towards the other end, when the thickness of the $\mathrm{Cu}-\mathrm{Ni}$ alloy reaches $100 \mathrm{~nm}$ and above, the quality of graphene has gradually stabilized.

As indicated earlier, we have also grown graphene on copper foils by the GD method in order to boost the monolayer ratio. The corresponding Raman measurement results are demonstrated in Figure 6. From Figure 6a, we can see that, by using the GD method, we can grow high-quality single-layer graphene on copper foil at $900{ }^{\circ} \mathrm{C}$. When the growth temperature is increased to $1000{ }^{\circ} \mathrm{C}$, however, some low quality and-most likely-bilayer graphene is seen to grow, and where the $2 \mathrm{D} / \mathrm{G}$ ratio decreases, the $\mathrm{D}$ peak rises and the number of defects increases. The reason is not yet clear, but this paper believes it could be explained as follows. Compared with the copper foil at $900{ }^{\circ} \mathrm{C}$, 
the surface of the copper foil at $1000{ }^{\circ} \mathrm{C}$ becomes rougher (see Figure 7) because it is closer to Cu's melting point $1083^{\circ} \mathrm{C}$. Eventually, the graphene quality deteriorates and some bilayer graphene starts to show up. The graphene quality is also worse compared with the graphene grown by the GD method on $\mathrm{Cu}-\mathrm{Ni}$ at the same temperature (see Figure 5a). The effect is attributed to the fact that in graphene growth $\mathrm{Ni}$ has a much higher catalytic ability than $\mathrm{Cu}$ [28]. Figure $6 \mathrm{~b}-\mathrm{d}$ shows the Raman mapping data measured in a $28 \mu \mathrm{m} \times 28 \mu \mathrm{m}(10 \times 10$ points $)$ graphene area grown on copper foil at $900{ }^{\circ} \mathrm{C}$ and transferred to its $\mathrm{SiO}_{2} / \mathrm{Si}$ substrate. The ratio of $\mathrm{I}_{\mathrm{D}}$ to $\mathrm{I}_{\mathrm{G}}$ is less than 0.35 , and the ratio of $\mathrm{I}_{\mathrm{G}} / \mathrm{I}_{2 \mathrm{D}}$ is mostly around 0.5 . This proves that the uniformity of the number of graphene layers is very good across the sample and the graphene is mainly single layer. Figure 8 shows the optical transmittance of the graphene grown at $900^{\circ} \mathrm{C}$ and then transferred to the glass substrate. It has a transmission rate of about $97.7 \%$ in almost the full wavelength band, in agreement with the expected value for standard monolayer graphene. Those results confirm that the GD technique proposed in this paper performs excellently during the graphene growth catalysis on copper foils at $900{ }^{\circ} \mathrm{C}$.

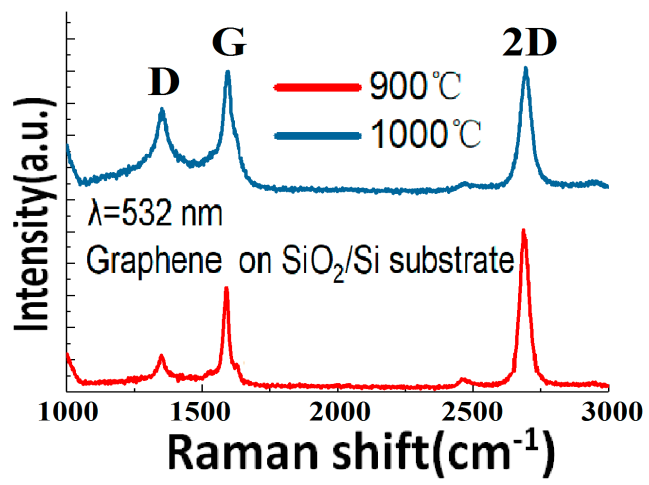

(a)

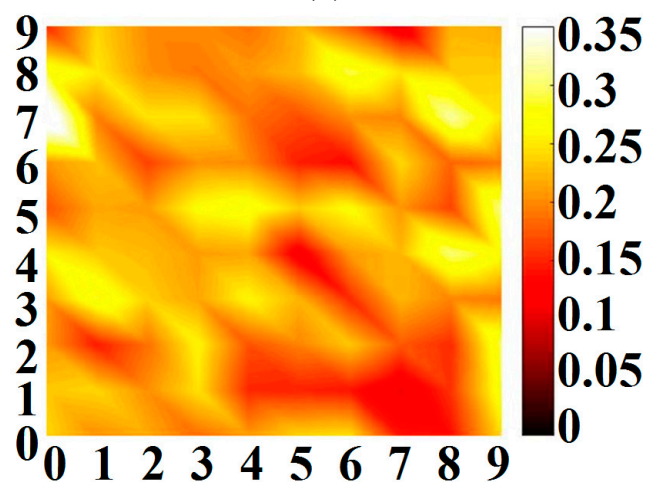

(c)

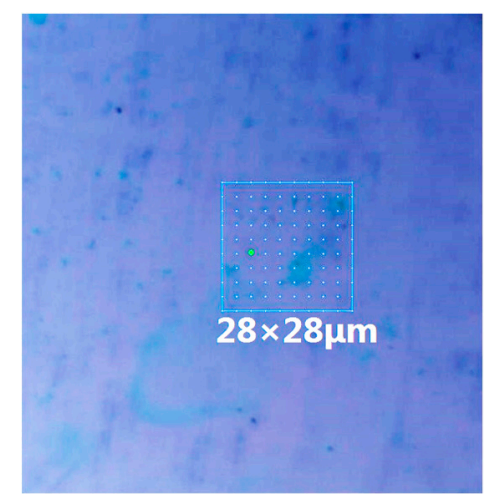

(b)

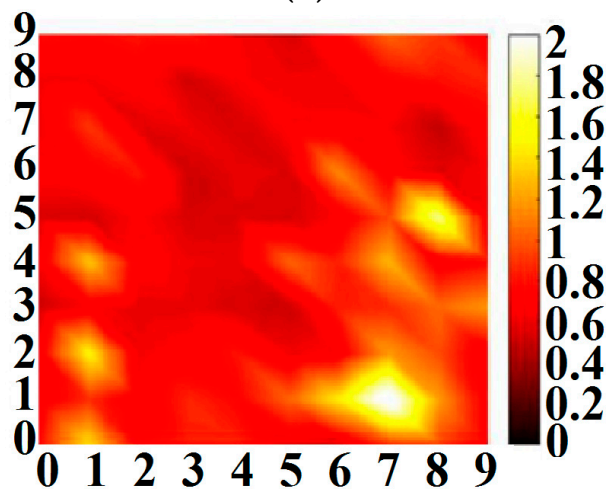

(d)

Figure 6. (a) Raman spectra of the graphene prepared by the GD method at $900{ }^{\circ} \mathrm{C}$ and $1000{ }^{\circ} \mathrm{C}$ by using copper foil as a catalyst. (b) Optical image (taken by Raman microscope) of a graphene thin film grown on copper foil at $900{ }^{\circ} \mathrm{C}$ and transferred to its $\mathrm{SiO}_{2} / \mathrm{Si}$ substrate. The $28 \mu \mathrm{m} \times 28 \mu \mathrm{m}$ part indicated by the square is the area for Raman mapping. (c,d) Raman mapping $(28 \mu \mathrm{m} \times 28 \mu \mathrm{m})$ of the $\mathrm{D} / \mathrm{G}$ and $\mathrm{G} / 2 \mathrm{D}$ ratios of the graphene grown on copper foil at $900{ }^{\circ} \mathrm{C}$ and transferred to its $\mathrm{SiO}_{2} / \mathrm{Si}$ substrate. In each image, there are $10 \times 10$ measured points and the color bar indicates the ratio. 


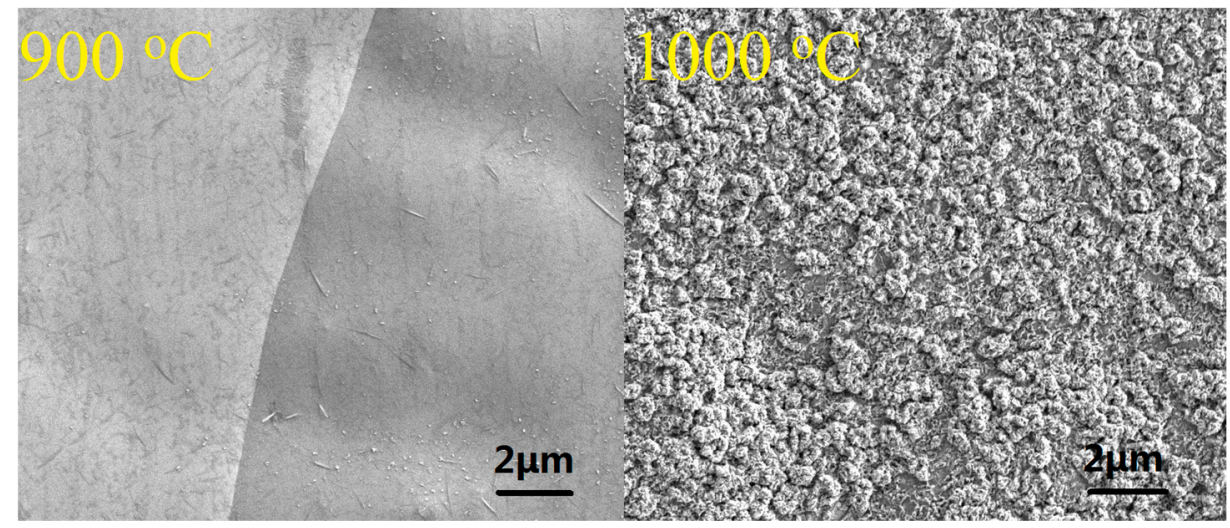

(a)

(b)

Figure 7. SEM images of the copper foils after coating with graphene at (a) $900{ }^{\circ} \mathrm{C}$ and (b) $1000{ }^{\circ} \mathrm{C}$.

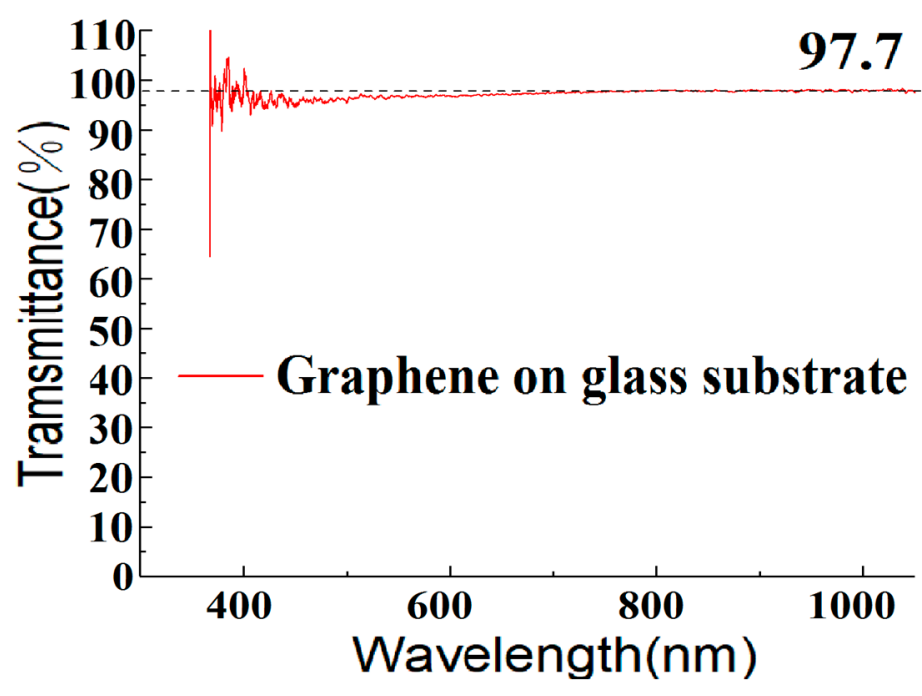

Figure 8. Optical transmittance of the as-grown graphene grown at $900{ }^{\circ} \mathrm{C}$ on $\mathrm{Cu}$ foil and transferred onto a glass substrate.

\section{Conclusions}

In this paper, we report a new type of graphene synthesis technology called GD deposition, using a standard PECVD machine. Compared to the traditional AD method, the GD technique uses a much smaller current, and the etching process of the graphite electrode that is used to ignite plasma is very gentle. The graphite electrode can be directly used as the carbon source for the graphene growth in a $\mathrm{H}_{2}$ and/or Ar plasma environment, and high-quality graphene thin films can be synthesized at about $900{ }^{\circ} \mathrm{C}$ on catalytic metals e.g., $\mathrm{Cu}-\mathrm{Ni}$ alloy and pure $\mathrm{Cu}$. The graphene production mechanism is a plasma etching of the graphite, followed by a carbon containing particle emission, where the particles are scattered towards the catalytic metal surfaces for graphene thin film formation. To our knowledge, this graphene production mode has never been reported before. It reveals that graphene sheets (not irregular flakes) can be obtained by gaseous discharge-based technology. The as-grown graphene is transferrable, and is characterized by Raman spectroscopy, SEM, and other means to prove the feasibility of the GD. It is found that the major factors during the graphene synthesis that can determine the material quality are the growth temperature and the type of catalytic metals, but not the gas ratios. This work shows that the GD graphene production model can be used to prepare graphene thin films without using carbon-containing gases such as methane and ethylene, which provides a new technology and a new insight for graphene synthesis. In future work, we will continue to improve the quality of graphene and increase the sample size. We will apply the graphene in 
semiconductor devices, such as current spreading layers of light-emitting diodes [29]. We will also adjust the experimental conditions and explore the interesting topic, whether the GD method can produce vertical graphene [30] or carbon nanotubes.

Author Contributions: Conceptualization, L.W., Y.D. and J.S.; methodology, L.W., Y.D. and J.S.; formal analysis, W.G.; resources, Y.X., J.D. and C.X.; data curation, L.W., F.X., Z.D. and L.L.; writing-original draft preparation, L.W. and W.G.; writing-review and editing, J.S.; supervision, J.S.; project administration, J.S.; funding acquisition, W.G. and J.S. All authors have read and agreed to the published version of the manuscript.

Funding: This research was funded by the National Key R \& D Program of China (2017YFB0403102) and the National Natural Science Foundation of China (11674016).

Conflicts of Interest: The authors declare no conflict of interest.

\section{References}

1. Rao, C.N.R.; Subrahmanyam, K.S.; Matte, H.S.S.R.; Abdulhakeem, B.; Govindaraj, A.; Das, B.; Kumar, P.; Ghosh, A.; Late, D.J. A study of the synthetic methods and properties of graphenes. Sci. Technol. Adv. Mater. 2010, 11, 054502. [CrossRef] [PubMed]

2. Tzalenchuk, A.; Lara-Avila, S.; Kalaboukhov, A. Towards a quantum resistance standard based on epitaxial graphene. Nat. Nanotechnol. 2010, 5, 186-189. [CrossRef] [PubMed]

3. Cheng, T.S.; Davies, A.; Summerfield, A.; Cho, Y.; Cebula, I.; Hill, R.J.A.; Mellor, C.J.; Khlobystov, A.N.; Taniguchi, T.; Watanabe, K.; et al. High temperature MBE of graphene on sapphire and hexagonal boron nitride flakes on sapphire. J. Vac. Sci. Technol. B 2016, 34, 02L101. [CrossRef]

4. Sun, J.; Cole, M.T.; Lindvall, N.; Teo, K.B.K.; Yurgens, A. Noncatalytic chemical vapour deposition of graphene on high-temperature substrates for transparent electrodes. Appl. Phys. Lett. 2012, 100, 022102.

5. Wang, Z.; Li, N.; Shi, Z.; Gu, Z. Low-cost and large-scale synthesis of graphene nanosheets by arc discharge in air. Nanotechnology 2010, 21, 175602. [CrossRef]

6. KraTschmer, W.; Lamb, L.D.; Fostiropoulos, K.; Huffman, D.R. Solid $\mathrm{C}_{60}$ : A new form of carbon. Nature 1990, 347, 354-358. [CrossRef]

7. Pham, T.V.; Kim, J.; Jung, J.Y.; Kim, J.H.; Cho, H.; Seo, T.H.; Lee, H.; Kim, N.D.; Kim, M.J. High areal capacitance of N-Doped graphene synthesized by arc discharge. Adv. Funct. Mater. 2019, 29, 1905511. [CrossRef]

8. Volotskova, O.; Levchenko, I.; Shashurin, A.; Raitses, Y.; Ostrikov, K.; Keidar, M. Single-step synthesis and magnetic separation of graphene and carbon nanotubes in arc discharge plasmas. Nanoscale 2010, 2, 2281-2285. [CrossRef]

9. Huang, L.; Wu, B.; Chen, J.; Xue, Y.; Geng, D.; Guo, Y.; Yu, G.; Liu, Y. Gram-scale synthesis of graphene sheets by a catalytic arc-discharge method. Small 2013, 9, 1330-1335. [CrossRef]

10. Shashurin, A.; Keidar, M. Synthesis of 2D materials in arc plasmas. J. Phys. D Appl. Phys. 2015, 48, 314007. [CrossRef]

11. Ahmadi, R.; Ahmadi, M.T.; Ismail, R. Carbon nano-particle synthesized by pulsed arc discharge method as a light emitting device. J. Electron. Mater. 2018, 47, 4003-4009. [CrossRef]

12. Ismail, R.A.; Mohammed, M.I.; Mahmood, L.H. Preparation of multi-walled carbon nanotubes/n-Si heterojunction photodetector by arc discharge technique. Opt. Int. J. Light Electron. Opt. 2018, 164, 395-401. [CrossRef]

13. Wu, Z.S.; Ren, W.; Gao, L.; Zhao, J.; Chen, Z.; Liu, B.; Tang, D.; Yu, B.; Jiang, C.; Cheng, H.M. Synthesis of graphene sheets with high electrical conductivity and good thermal stability by hydrogen arc discharge exfoliation. ACS Nano 2009, 3, 411-417. [CrossRef] [PubMed]

14. Sun, J.; Lindvall, N.; Cole, M.; Angel, K.T.T.; Wang, T.; Teo, K.B.K.; Chua, D.H.C.; Liu, J.; Yurgens, A. Low partial pressure chemical vapour deposition of graphene on copper. IEEE Trans. Nanotechnol. 2012, 11, 255-260. [CrossRef]

15. De la Rosa, C.J.L.; Sun, J.; Lindvall, N.; Cole, M.T.; Nam, Y.; Löffler, M.; Olsson, E.; Teo, K.B.K.; Yurgens, A. Frame assisted $\mathrm{H}_{2} \mathrm{O}$ electrolysis induced $\mathrm{H}_{2}$ bubbling transfer of large area graphene grown by chemical vapour deposition on $\mathrm{Cu}$. Appl. Phys. Lett. 2013, 102, 022101. [CrossRef]

16. Takesaki, Y.; Kawahara, K.; Hibino, H.; Okada, S.; Tsuji, M.; Ago, H. Highly uniform bilayer graphene on epitaxial Cu-Ni(111) alloy. Chem. Mater. 2016, 28, 4583-4592. [CrossRef] 
17. Dong, Y.; Xie, Y.; Xu, C.; Fu, Y.; Fan, X.; Li, X.; Wang, L.; Xiong, F.; Guo, W.; Pan, G.; et al. Transfer-free, lithography-free and fast growth of patterned CVD graphene directly on insulators by using sacrificial metal catalyst. Nanotechnology 2018, 29, 365301. [CrossRef]

18. Ishigami, M.; Chen, J.H.; Cullen, W.G.; Fuhrer, M.S.; Williams, E.D. Atomic structure of graphene on $\mathrm{SiO}_{2}$. Nano Lett. 2007, 7, 1643-1648. [CrossRef]

19. Ago, H.; Ito, Y.; Mizuta, N.; Yoshida, K.; Hu, B.; Orofeo, C.M.; Tsuji, M.; Ikeda, K.; Mizuno, S. Epitaxial chemical vapour deposition growth of single-Layer graphene over cobalt film crystallized on sapphire. ACS Nano 2010, 4, 7407-7414. [CrossRef]

20. Bruce, C.E.R. Transition from glow to arc discharge. Nature 1948, 161, 521-522. [CrossRef]

21. Xie, L.; Jiao, L.; Dai, H. Selective etching of graphene edges by hydrogen plasma. J. Am. Chem. Soc. 2010, 132, 14751-14753. [CrossRef] [PubMed]

22. Davydova, A.; Despiau-Pujo, E.; Cunge, G.; Graves, D.B. Etching mechanisms of graphene nanoribbons in downstream $\mathrm{H}_{2}$ plasmas: Insights from molecular dynamics simulations. J. Phys. D Appl. Phys. 2015, 48, 195202. [CrossRef]

23. Glad, X.; de Poucques, L.; Jaszczak, J.A.; Belmahi, M.; Ghanbaja, J.; Bougdira, J. Plasma synthesis of hexagonal-pyramidal graphite hillocks. Carbon 2014, 76, 330-340. [CrossRef]

24. Wu, S.; Yang, R.; Shi, D.; Zhang, G. Identification of structural defects in graphitic materials by gas-phase anisotropic etching. Nanoscale 2012, 4, 2005-2009. [CrossRef]

25. Ferrari, A.C.; Meyer, J.C.; Scardaci, V.; Casiraghi, C.; Lazzeri, M.; Mauri, F.; Piscanec, S.; Jiang, D.; Novoselov, K.S.; Roth, S.; et al. Raman spectrum of graphene and graphene layers. Phys. Rev. Lett. 2006, 97, 187401. [CrossRef]

26. Yu, Q.; Lian, J.; Siriponglert, S.; Li, H.; Chen, Y.P.; Pei, S. Graphene segregated on Ni surfaces and transferred to insulators. Appl. Phys. Lett. 2008, 93, 113103. [CrossRef]

27. Sun, J.; Nam, Y.; Lindvall, N.; Cole, M.; Kenneth, K.B.; Park, Y.W.; Yurgens, A. Growth mechanism of graphene on platinum: Surface catalysis and carbon segregation. Appl. Phys. Lett. 2014, 104, 152107. [CrossRef]

28. Dong, Y.; Guo, S.; Mao, H.; Xu, C.; Xie, Y.; Deng, J.; Wang, L.; Du, Z.; Xiong, F.; Sun, J. In situ growth of CVD graphene directly on dielectric surface toward application. ACS Appl. Electron. Mater. 2020, 2, 238-246. [CrossRef]

29. Xiong, F.; Guo, W.; Feng, S.; Li, X.; Du, Z.; Wang, L.; Deng, J.; Sun, J. Transfer-free graphene-like thin films on GaN LED epiwafers grown by PECVD using an ultrathin Pt catalyst for transparent electrode applications. Materials 2019, 12, 3533. [CrossRef]

30. Li, L.; Dong, Y.; Guo, W.; Qian, F.; Xiong, F.; Fu, Y.; Du, Z.; Xu, C.; Sun, J. High-responsivity photodetectors made of graphene nanowalls grown on Si. Appl. Phys. Lett. 2019, 115, 081101. [CrossRef] 